\title{
RELAÇÕES ÉTNICO-RACIAIS E FORMAÇÃO DOCENTE NA EDUCAÇÃO INFANTIL
}

\author{
ETHNIC-RACIAL RELATIONS AND TEACHING TRAINING IN CHILDREN'S \\ EDUCATION
}

Moacir Silva de Castro Mestre em Educação pela Universidade Nove de Julho - UNINOVE Docente do Instituto Federal de Educação, Ciência e Tecnologia de São Paulo - IFSP, Registro - SP - Brasil moacir.castro@ifsp.edu.br

Resumo: $\mathrm{O}$ texto tem como objeto a análise da formação docente na educação infantil na perspectiva das relações étnico-raciais. Assim, problematiza inicialmente concepções de criança, trazendo diferentes leituras que a caracterizam. Defende que a formação de professores para a educação infantil, quando considera princípios de uma educação para as relações étnico-raciais, contribui para problematizar e diminuir práticas racistas, que são comuns nos discursos que predominam nesta fase da educação. Analisa ainda essa temática na legislação brasileira e em documentos normativos como as diretrizes curriculares para o curso de pedagogia. Critica a maneira como a formação docente não tem contribuído para o avanço dessa questão, devido, sobretudo, a estrutura dos cursos de pedagogia, que em geral secundarizam questões cotidianas das escolas. Por fim, assevera a importância de os cursos de formação de professores das séries iniciais darem mais atenção às concepções que os docentes constroem de criança, permitindo especialmente que essas habilidades os auxiliem no trato da diversidade, bem como contribuir para que essa formação em frente as diferentes formas de racismo e preconceito presentes nos sistemas de ensino.

Palavras-chave: Educação Infantil. Formação Docente. Relações Étnico-Raciais

\begin{abstract}
The purpose of the text is to analyze teacher education in children's education from the perspective of ethnic-racial relations. Thus, initially problematizes conceptions of children, bringing different readings that characterize it. He argues that teacher training for early childhood education, when considering principles of education for ethnic-racial relations, contributes to problematizing and reducing racist practices that are common in the discourses that predominate at this stage of education. It also analyzes this theme in Brazilian legislation and in normative documents such as the curricular guidelines for the pedagogy course. It criticizes the way in which teacher training has not contributed to the advancement of this issue, mainly due to the structure of the pedagogy courses, which generally subordinate daily issues of schools. Finally, it affirms the importance of teacher education courses in the initial grades to give more attention to the conceptions that teachers construct as children, especially allowing these skills to help them to deal with diversity, as well as to forms of racism and prejudice present in educational systems.
\end{abstract}

Keywords: Early Childhood Education. Teacher Training. Ethnic-Racial Relations

\section{Introdução}

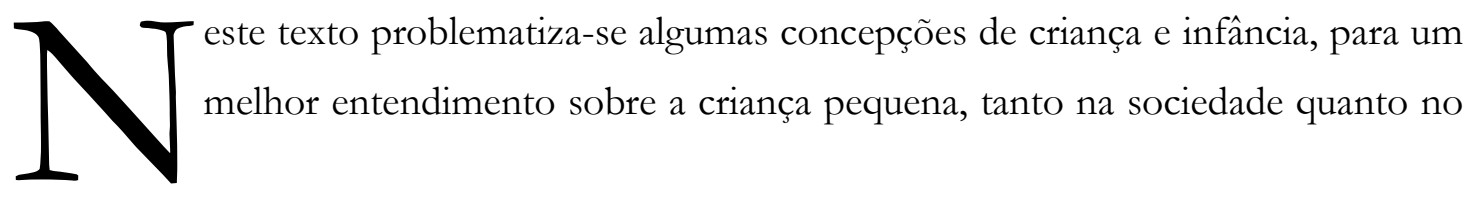


espaço escolar, e lançamos luz sobre a formação docente na perspectiva da educação das relações étnico-raciais, especialmente no trabalho pedagógico da escola da infância.

Entende-se também que as práticas transformadoras dos processos pedagógicos da Educação Básica serão alcançadas com maior eficácia na medida em que a categoria docente que atua neste seguimento for submetida a processos formativos que dialoguem com as demandas mais latentes, como os mecanismos de trato a serem desenvolvidos pela escola com as questões de identidade e diversidade no espaço escolar.

O Brasil, como membro da Organização das Nações Unidas (ONU), ratificou a Declaração Universal dos Direitos Humanos de 1948 e, em 1988, incorporou alguns princípios desta Declaração à Constituição da República Federativa do Brasil. Nessa perspectiva entende-se também uma educação para as relações étnico-raciais como uma educação na direção da garantia dos direitos humanos, sobretudo em se tratando de uma educação que visa reconhecer a dignidade humana e condenar qualquer prática de racismo.

Nesse sentido é necessário contribuir para que os docentes, notadamente os que atuam na Educação Infantil, sejam capazes de analisar criticamente a realidade social, de modo que também possam estabelecer relações entre educação, discriminação racial, racismo e direitos humanos.

\section{Concepções de criança e infância na Educação Básica}

Barbosa (2006) assevera que as noções que temos hoje sobre criança e infância trazem significações sociais, gerais e imprecisas. De acordo com a autora “[...] a infância não é uma experiência universal, nem natural, de duração fixa, mas está vinculada aos significados dados pela cultura e pela história individual de cada um" (BARBOSA, 2006, p. 74). São diversos os mecanismos sociais que determinam e caracterizam a ideologia que serve de substrato para o conceito de criança nas diferentes sociedades.

De acordo com Stearns (2006), todas as sociedades lidam, lidaram e lidarão com a infância e a criança, sendo possível identificar, nessas formas de lidar, tanto características padronizadas quanto variações ao longo da história e ainda no contexto atual. Como exemplo de padronização, o autor destaca a fragilidade em relação às outras espécies que necessitam de cuidados especiais para a sua sobrevivência, alguma preparação para o estágio adulto, orientações quanto aos papéis de gênero, entre outros. Em relação às variações o autor destaca diferenciações quanto à duração ou ao término da infância, admissão ou não do trabalho pesado infantil, naturalização da 
mortalidade nessa faixa etária, imputação ou não de castigos físicos. Essas são questões que permeiam as diferentes sociedades no trato com suas crianças.

Segundo esse autor, antes de se abordar as categorias criança ou infância, é necessário situar-se no tempo e no espaço com as seguintes questões: Estamos falando das crianças que ajudavam as mulheres na coleta de sementes ou da infância perambulante das tribos coletoras e caçadoras? Das crianças nobres sendo duramente educadas para preservarem os costumes e riquezas de sua ascendência ou das crianças vendidas como escravas para ajudar na economia familiar na China clássica? Das crianças que dançam em rituais religiosos ou da infância vivenciada aos cuidados de tutores na Grécia ou em Roma? Das crianças sendo cuidadosamente amamentadas e educadas por suas mães ou da infância abreviada por um casamento aos oito anos de idade na Índia? Da infância escolarizada entre meninos e meninas ou de crianças trabalhadoras em péssimas condições no Japão? Das crianças dos campos de concentração do holocausto? Das crianças soldados na Ásia e na África ou da infância utópica defendida pelos organismos internacionais? Da criança como criação do Estado na Rússia ou da infância institucionalizada do século XX? Das crianças prostituídas ou da infância vivenciada nas ruas, nos sinais de trânsito no século XXI?

Enfim, para todas essas questões podem ser elaboradas respostas diferentes, o que levaria a caracterizar, particularmente, cada criança e sua infância. Por isso que os sentidos atribuídos à criança e à infância são históricos e oriundos de construções sociais, organização política, cultural e econômica de cada povo em um determinado tempo e espaço.

Compreender os conceitos de criança e infância implica entender a importância da etapa da Educação Básica destinada às crianças pequenas. Lopes (2006) considera a Educação Infantil como um fenômeno multifacetado, marcado por paradoxos, contradições, dinamicidade e complexidade. Às instituições de Educação Infantil orienta-se que desempenhem seus papéis sem dissociar o cuidar do educar ${ }^{1}$, uma vez que essa articulação busca assegurar um dos direitos fundamentais da criança pequena, o de aprender e desenvolver de forma plena e integral suas capacidades humanas, podendo acessar a cultura produzida e acumulada pela humanidade e também produzindo culturas na relação que estabelece com o mundo em que está inserida.

Moralizar, educar, domesticar, entre outros, eram verbos utilizados nesse período e influenciados pelas ideias difundidas no século XVIII. Esses termos forjaram uma visão que perdura até os nossos dias para se referir às crianças. Essas ideias traziam uma concepção de criança como sujeito ingênuo, inocente e de fácil modelação de caráter. As famílias incutiam nas crianças valores que eram valorizados pela burguesia. As escolas refletiam essa lógica, servindo como 
espaços de controle social e preocupados com a contenção da delinquência infantil e questões de ordem moral (CAVALLEIRO, 2006).

Esse período marcou e deixou a Educação Infantil com um viés excessivamente cuidador e assistencialista nas creches (crianças de 0 a 3 anos), enquanto nas pré-escolas (crianças de 4 a 6 anos) importava práticas escolarizadas adotadas no ensino primário (7 a 10 anos). Nesse cenário, o debate e a devida importância ao aspecto da socialização na Educação Infantil, na perspectiva do cuidar-educar, foi sendo secundarizado, de modo que reflexões sobre diversidade também foram silenciadas.

A formação docente para uma educação das relações étnico-raciais possibilitará reflexões e questionamentos sobre a mentalidade discriminadora e racista presente na história do Brasil, sobretudo nas bases teóricas construídas historicamente e que entendiam como harmoniosa as relações sociais entre as diferentes etnias.

Com a promulgação da Constituição Federal de 1988, da Lei de Diretrizes e Bases da Educação Nacional (lei n. 9394 de 1996) e do Estatuto da Criança e do Adolescente (ECA) de 1990, consequências do processo de redemocratização do Brasil, a Educação Infantil ampliou seu espaço no campo de pesquisas, reflexões teóricas e em várias frentes, e também no que se refere à dimensão da formação de professores.

Nos dias atuais, compreende-se que, nas práticas da Educação Infantil, docentes e crianças iniciam processos de percepção das semelhanças e diferenças suas e de seus grupos, ao mesmo tempo em que reconhecem as próprias peculiaridades e características. Porém, dependendo dos referenciais afetivos, sociais e culturais que lhe forem oferecidos, esse processo pode ser mais agregador ou desagregador para a construção das identidades desses sujeitos. De acordo com Bento (2012), a identidade do sujeito está intimamente ligada à relação que estabelece com nosso grupo e, particularmente, com nosso próprio corpo.

No que se refere à criança negra, estereótipos depreciativos são representações corriqueiramente marcadas no corpo, principalmente entre os veículos de comunicação de massa no Brasil. Cabelo ruim, corpo sujo, feio e malcheiroso também são ideologias que são difundidas deliberadamente pelos veículos de comunicação midiáticos. As crianças por vezes apresentam desconforto ou vergonha de seu pertencimento racial, fenômeno que já começa a surgir na etapa da Educação Infantil. O corpo negro tende a ser negado frente a padrões de beleza, estética e saúde convencionalmente tidos como padrões a serem seguidos. Cavalleiro (2006) ressalta que cotidianamente algumas escolas reforçam esses comportamentos depreciativos, com suas práticas 
pautadas na disciplina e na higiene. Nessa perspectiva, o negro é visto por vezes como indisciplinado e malcheiroso. Dessa forma, o racismo na primeira infância atinge diretamente o corpo, o modo como ele é construído, querido ou negado.

Silva et al (2002) afirmam que já nesta etapa educativa, para diferenciar crianças fáceis ou difíceis para se trabalhar, há uma tendência docente, na maioria das vezes, de rotular como difíceis as crianças negras, notadamente os meninos. Essas crianças, em geral, recebem adjetivos pautados em comportamentos considerados ruins como "demora mais para aprender a dividir os objetos", “ele é terrível, não para, não fica quieto" ou "é agitado, agressivo, teimoso, levado", entre outros (BENTO, 2012, p. 21). As crianças consideradas fáceis - na maioria dos casos meninas e brancas - recebem adjetivos como "espertas, bem-comportadas, com bom desenvolvimento, inteligentes" etc. (idem).

Esses elementos indicam que as representações que as escolas construíram e constroem cotidianamente sobre os negros corroboram para o desenvolvimento de práticas discriminatórias, ainda que isso ocorra sem que a escola e docentes percebam. A partir da constatação dessas construções, a escola pode se organizar para promover às crianças negras e brancas oportunidades de vivenciar momentos de construção positiva de sua identidade. Oferecer a elas possibilidades de desenvolvimento social e educacional desigual leva à construção de referências negativas porque,

[...] no convívio com os estereótipos negativos, as crianças aprendem a internalizar sentimentos positivos ou negativos sobre si mesmas, e a professora é uma das principais pessoas que vai lhes possibilitar informações sobre o quê elas são, a partir do fornecimento dos principais dados sobre seu desenvolvimento, suas capacidades e habilidades. (SILVA et al, 2002, p. 139)

Tratamentos desiguais foram observados por Oliveira (2004, p. 122) ao investigar crianças bem pequeninas em instituição de Educação Infantil, conforme se lê a seguir:

\footnotetext{
Durante qualquer refeição, Vagner (negro, 1 ano) era posto no cadeirão, pois, de acordo com Marli, "ele não dá sossego" (...). Igor (branco, 1 ano) não fazia nada menos terrível que Vagner. As travessuras realizadas pelos dois eram as mesmas: empurrar berços, subir em cima da mesa, arrastar as cadeiras, bater nos colegas, etc. No entanto, o diferencial entre eles era a cor.
}

Tal constatação também é evidenciada por Dias (2007, p. 250):

$\mathrm{Na}$ educação infantil a gente já sentiu essa questão da diferença do tratamento dos profissionais em relação à criança negra e à criança branca. [...] As crianças negras não têm tanto colo, chamego, aconchego como as crianças brancas. 
Analisar essa constatação no ambiente escolar é fundamental para o trato com a construção da identidade, porque a interação que a criança mantém com seu corpo pode, por vezes, ser marcada pela recusa que a escola, os professores e outras crianças apresentam diante desse corpo. Se o corpo não for querido, a criança tenderá a não se sentir bem com ele, o que ocasionará um impacto na autoestima. Essa situação pôde ser identificada no comportamento de crianças brancas em relação às crianças negras, conforme relato de uma professora que participou do estudo realizado por Dias (2007, p. 250):

\footnotetext{
A criança falou: "Não quero essa menina perto de mim [...] essa neguinha perto de mim" (na festa junina). "Ah, não quero dançar com ela (criança negra)". A criança não diz especificamente por que não quer dançar... mas você tem de ter o jogo de cintura como professora para montar os pares de maneira que a criança negra seja bem aceita como par.

[...] Às vezes ela (a criança negra) não é convidada para fazer parte da brincadeira. São poucos os que a chamam, os que a convidam. Elas (as crianças brancas) dão preferência às outras crianças brancas para ficar brincando.
}

A fala da professora na investigação realizada pela pesquisadora Lucimar Dias revela a importância dos docentes da Educação Infantil, assim como as escolas e a comunidade escolar de maneira geral, buscarem formação para tratar das questões relativas à diversidade, sobretudo as que se relacionam com a dimensão das relações étnico-raciais. Cabe ter em vista que as questões que as cercam são fruto do processo histórico da humanidade e que, portanto, não necessitam servir para hierarquizar as relações sociais, mas, sim, podem contribuir para melhorar as relações entre as crianças, contribuindo assim para a melhoria das relações na sociedade.

\section{A formação docente para as relações étnico-raciais na escola da infância}

A formação docente no Brasil, historicamente, tem sofrido com questões conjunturais. Alguns se referem ao lugar ocupado pelos cursos nas instituições de Ensino Superior, depois, existe a diferenciação feita entre os professores polivalentes, que atuam na Educação Infantil e nas séries iniciais do Ensino Fundamental, em relação aos professores especialistas de disciplinas específicas dos anos finais do Ensino Fundamental e do Médio. Quando se mencionam as políticas públicas no tocante à educação, o assunto formação docente toma posição de frente, seja nas reformas que têm sido implementadas nas propostas de formação de professores ou na formação inicial e continuada. Sobre a importância da formação docente na Educação Básica, o texto abaixo serve como ponto de partida para nossas reflexões:

De todos os investimentos para a Educação Básica, a formação do professor é o de melhor custo benefício e o que pode dar maior sustentabilidade a longo prazo para as 
políticas de melhoria da qualidade da educação básica. Um bom professor beneficia pelo menos 25 a 30 alunos. Vale o mesmo raciocínio, só que ao revés, para o mau professor, (MELLO, 1999, p. 9)

A reflexão que a afirmação suscita é de ir além da necessidade de se investir efetiva e seriamente na formação docente, sob o entendimento de que muitos professores não são "maus profissionais" porque querem, mas sim por conta do processo de formação pelo qual passaram não ter oferecido suporte suficiente para que esse profissional obtivesse formação adequada para o exercício da docência.

Ainda sobre a formação docente para o exercício nas etapas da Educação Básica, Gatti (2010) coordenou pesquisa que analisou ementa de 71 cursos de Pedagogia do Brasil e constatou distanciamento entre o que é proposto nos cursos de formação inicial de professores e aquilo que é preconizado nos documentos oficiais, conforme afirmação da própria autora:

\begin{abstract}
Nas ementas observou-se um evidente desequilíbrio na relação teoria-prática, em favor dos tratamentos mais teóricos, de fundamentos, política e contextualização e que a escola, como instituição social e de ensino, é elemento quase ausente nas ementas, o que leva a pensar numa formação de caráter mais abstrato e pouco integrado ao contexto concreto onde o profissional-professor vai atuar.

Pelo estudo citado pode-se inferir que fica bem reduzida a parte curricular que propicia o desenvolvimento de habilidades profissionais específicas para a atuação nas escolas e nas salas de aula. Assim, a relação teoria-prática como proposta nos documentos legais e nas discussões da área também se mostra comprometida desde essa base formativa. (GATTI, 2010, p. 137)
\end{abstract}

Um dos documentos a ser citado trata-se da Resolução que institui as Diretrizes Curriculares Nacionais para o Curso de Graduação em Pedagogia ${ }^{2}$. Além de definir a formação para a Educação Infantil, compreende a docência como ação educativa do processo pedagógico metódico e intencional, constituído em relações sociais, étnico-raciais e produtivas, na qual influenciam conceitos, princípios e objetivos da Pedagogia, desenvolvendo-se na articulação entre conhecimentos científicos e culturais, valores éticos e estéticos inerentes aos processos de aprendizagem, de socialização e de construção do conhecimento, no âmbito do diálogo entre diferentes visões de mundo. Ou seja, enfatiza a possibilidade do futuro docente, mediado pelas diversas fontes de conhecimentos, construir saberes teórico-práticos que os subsidiem para o exercício profissional em diferentes funções do magistério e da educação não formal.

A seguir destacamos alguns itens do Art. $5^{\circ}$ das Diretrizes Curriculares, nos quais estão contidas ações que o egresso do curso de Pedagogia deve estar apto em desempenhá-las: 
I - atuar com ética e compromisso com vistas à construção de uma sociedade justa, equânime, igualitária;

II - compreender, cuidar e educar crianças de zero a cinco anos, de forma a contribuir, para o seu desenvolvimento nas dimensões, entre outras, física, psicológica, intelectual, social [...];

VIII - promover e facilitar relações de cooperação entre a instituição educativa, a família e a comunidade;

IX - identificar problemas socioculturais e educacionais com postura investigativa, integrativa e propositiva em face de realidades complexas, com vistas a contribuir para superação de exclusões sociais, étnico-raciais, econômicas, culturais, religiosas, políticas e outras;

$\mathrm{X}$ - demonstrar consciência da diversidade, respeitando as diferenças de natureza ambiental-ecológica, étnico-racial, de gêneros, faixas geracionais, classes sociais, religiões, necessidades especiais, escolhas sexuais, entre outras;

XV - utilizar, com propriedade, instrumentos próprios para construção de conhecimentos pedagógicos e científicos;

$\mathrm{XVI}$ - estudar, aplicar criticamente as diretrizes curriculares e outras determinações legais que lhe caiba implantar, executar, avaliar e encaminhar o resultado de sua avaliação às instâncias competentes. (BRASIL, 2006, grifos nossos)

Os trechos destacados demonstram a dimensão de algumas expectativas depositadas nos professores ingressantes nas escolas de Educação Básica. Ao considerar, especificamente os conteúdos dos itens grifados seria de se supor que os cursos de Pedagogia preparassem os futuros profissionais da educação para implementação das leis n. 10.639/2003 e 11.645/2008, traduzidas nas Diretrizes Curriculares Nacionais para a Educação das Relações Étnico-Raciais (BRASIL, 2009), e para a implementação do Plano Nacional de Educação (PNE - 2014-2024) cuja estratégia 7.25 da meta 7, que estabelece a qualidade da Educação Básica em todas as suas etapas, propõe:

garantir nos currículos escolares conteúdos sobre a história e as culturas afro-brasileira e indígenas e implementar ações educacionais, nos termos das Leis nos 10.639 , de 9 de janeiro de 2003, e 11.645, de 10 de março de 2008, assegurando-se a implementação das respectivas diretrizes curriculares nacionais, por meio de ações colaborativas com fóruns de educação para a diversidade étnico-racial, conselhos escolares, equipes pedagógicas e a sociedade civil.

Além disso, há desde 2006, o Plano Nacional de Educação em Direitos Humanos (PNEDH) (BRASIL, 2009), que define concepções, princípios e ações programáticas em cinco eixos, dentre eles, três estão relacionados ao campo da educação: I. Educação Básica; Educação Superior; Educação Não Formal. Mesmo que na última década exista no Brasil tantas legislações voltadas para uma Educação em Direitos Humanos e para uma Educação para as Relações ÉtnicoRaciais, constata-se que ainda é um desafio superar processos excludentes, desiguais e opressores. Entretanto, como defende Freire (1996, p. 138),

No fundo diminuo a distância que me separa das condições malvadas em que vivem os explorados, quando, aderindo realmente ao sonho de justiça, luto pela mudança radical do mundo e não apenas espero que ela chegue porque se disse que chegará. 
Com esse espírito esperançoso, que não é de quem espera, mas de quem vai à luta por uma educação libertadora e por outro mundo possível - menos desigual e mais justo -, que Paulo Freire escreveu na obra "Pedagogia da Autonomia", que construir saberes necessários à prática docente exigem, dentre outros: respeito aos saberes dos educandos; criticidade; estética e ética; risco, aceitação do novo e rejeição a qualquer forma de discriminação; reflexão crítica sobre a prática, reconhecimento e assunção da identidade cultural, reconhecer que a educação é ideológica; saber escutar; disponibilidade para o diálogo e, compreender que a educação é uma forma de intervenção no mundo.

Se tivermos professores e professoras preparados para enfrentarem os desafios de uma nova escola que, como afirma Martins (2013, p. 3),

[...] não só acolhe a diferença, mas trabalha incorporando a diversidade, o processo de
formação de professores também ganha uma nova roupagem. Antes de se preocupar
com a formação de um técnico ou um mero transmissor acrítico e mecânico de
conhecimentos e informações, necessitamos formar um profissional preocupado em
construir, junto às crianças, conhecimentos atrelados a uma prática comprometida com
a apropriação da cultura e de um saber acumulado historicamente, num processo de
inclusão que levará consequentemente à promoção da democratização e equidade social.

$\mathrm{Na}$ perspectiva da educação libertadora, Freire (1996) valoriza os saberes da experiência produzidos na e pela cultura de quem é partícipe do ato de conhecer: educadores e educandos. Nesse sentido, a formação continuada de professores é de fundamental importância para mantêlos permanentemente no processo de construção de novos conhecimentos.

Lamentavelmente, nas últimas duas décadas, a formação continuada de professores tornouse, equivocadamente, um mecanismo de minimização dos impactos de uma formação inicial deficitária pela qual passam alguns professores. Ainda que essa formação se realize no nível superior, por vezes desponta a necessidade de melhorar as ferramentas recebidas pelo professor ao longo de sua primeira graduação. Por outro lado, entende-se que, ao invés de desempenhar um papel de compensação da formação inicial, a formação continuada deveria protagonizar o papel de valorização tanto da prática cotidiana dos professores quanto dos conhecimentos acadêmicos acumulados nas universidades, visando à relação teórico-prática no trabalho do professor. Constitui, portanto, um lugar privilegiado para aprimorar a formação docente, na troca de saberes e experiências acumuladas pelos professores, interação e geração de trabalhos interdisciplinares etc.

Como declara Giroux (1997, p. 161),

Encarar os professores como intelectuais também fornece uma vigorosa crítica teórica das ideologias tecnocráticas e instrumentais subjacentes à teoria educacional que separa a conceitualização, planejamento e organização curricular dos processos de implementação e execução. É importante enfatizar que os professores devem assumir responsabilidade ativa pelo levantamento de questões sérias acerca do que ensinam, como devem 
ensinar, e quais são as metas mais amplas pelas quais estão lutando. Isto significa que eles devem assumir um papel responsável na formação dos propósitos e condições de escolarização. [...].

O planejamento e o desenvolvimento das atividades educativas são aprendizados intrínsecos aos cursos de formação de professores, tanto inicial quanto continuada, aos quais devem ser incorporados conhecimentos históricos, filosóficos, antropológicos, sociológicos, políticos e culturais pautados em princípios como democracia e ética, pois esse profissional lidará com uma gama de informações diversificadas, teóricas e práticas, que se concretizarão no cotidiano do exercício da profissão.

Por esse motivo é que se julga ser importante problematizar as concepções que docentes têm de criança e de infância, pois elas expressam relações estabelecidas entre adultos e crianças que impactam diretamente na proposta, nos planos e na organização das escolas. Se conhecidos e respeitados pelos adultos, os direitos conferidos historicamente a todas as crianças têm mais chances de serem efetivados. Busca-se nos processos formativos maior sensibilidade e olhares mais atentos, na medida em que as diferenças se apresentam no dia-a-dia das crianças e precisam ser lidas e decodificadas ${ }^{3}$ pelas professoras nas relações que se estabelecem entre as crianças, adultos e todos que os cercam.

Os sujeitos que convivem e trabalham diariamente com as crianças também possuem suas singularidades e estão imersos em determinadas culturas e valores que orientam suas relações com o outro. Colocar-se contra qualquer forma de discriminação é tarefa de professores e profissionais escolares, pois, dessa forma, estarão reconhecendo um princípio de igualdade de tratamento que nos é garantido pela Constituição Federal de 1988:

Todos são iguais perante a lei, sem distinção de qualquer natureza, garantindo-se aos brasileiros e aos estrangeiros residentes no país a inviolabilidade do direito à vida, à liberdade, à igualdade, à segurança, à propriedade 4 .

Entende-se, portanto, que professores e demais adultos que convivem cotidianamente com crianças não se omitam diante de qualquer manifestação de violação dos direitos desses sujeitos, pois existem mecanismos legais como o $\mathrm{ECA}^{5}$ que também as protege nessas situações. É importante também que os profissionais que lidam com as crianças se mobilizem para que os direitos garantidos na lei se efetivem, assegurando às crianças e aos adolescentes possibilidades de 
pleno desenvolvimento de suas capacidades humanas. Isso denota compromisso de todos em cuidar e educar com responsabilidade.

\section{Considerações finais}

Entende-se que aproximar reflexões sobre práticas pedagógicas que lancem luz sobre a educação para as relações étnico-raciais junto à docentes da Educação Infantil são de fundamental importância para que a escola da infância alcance seus objetivos de proporcionar às crianças, desde a mais tenra idade, um espaço no qual essas tenham sua individualidade e peculiaridade respeitadas e valorizadas.

Este texto tem como objetivo ser mais uma contribuição ao debate, não só em relação ao contato com um tema relevante para a sociedade, e que está na base das reflexões sociais do passado e do presente, mas também possibilitar aos docentes da educação básica, especialmente os que atuam na educação infantil, um conjunto de perspectivas e possibilidades para tratamento de questões que surgem no cotidiano das escolas. Assim procuramos organizar as discussões de maneira a permitir reflexões para as mudanças necessárias nas práticas docentes no trato com as relações étnico-raciais na escola da infância.

Além disso, o texto busca servir de incentivo para novas reflexões aos docentes que atuam na educação infantil, na medida em que se trata de um campo de pesquisa que há muito a se problematizar para que os avanços necessários também sejam alcançados por meio da formação docente.

\section{Notas}

${ }^{1}$ De acordo com o Referencial Curricular Nacional para a Educação Infantil (RCNEI) esse aspecto se resume em "[...] propiciar situações de cuidados, brincadeiras e aprendizagens orientadas de forma integrada e que possam contribuir para o desenvolvimento das capacidades infantis de relação interpessoal, de ser e estar com os 
outros em uma atitude básica de aceitação, respeito e confiança, e o acesso, pelas crianças, aos conhecimentos mais amplos da realidade social e cultural”. (BRASIL, 1998, v. 1, p. 23).

${ }^{2}$ Resolução CNE/CP Nº 1, de 15 de Maio de 2006. Diário Oficial da União, 16 de maio de 2006, Seção 1, p.

${ }^{3}$ No sentido que Paulo Freire dá a essa palavra, ou seja, a capacidade de ler o mundo.

${ }^{4}$ Capítulo I, Artigo $5^{\circ}$ da Constituição da República Federativa do Brasil de 1988.

${ }^{5}$ Estatuto da Criança e do Adolescente. Lei 8.069, de 13 de Julho de 1990.

\section{Referências}

BARBOSA, Maria Carmem Silveira. Por amor e por força: rotinas na Educação Infantil. Porto Alegre: Artmed, 2006.

BENTO, Maria Aparecida da Silva (Org.). Práticas pedagógicas para igualdade racial na educação infantil. São Paulo: Centro de Estudos das Relações de Trabalho e Desigualdade (CEERT), 2012.

BRASIL. COMITÊ NACIONAL DE EDUCAÇÃO EM DIREITOS HUMANOS. Plano Nacional de Educação em Direitos Humanos. Secretaria Especial dos Direitos Humanos, Ministério da Educação, Ministério da Justiça, UNESCO. Brasília-DF, 2009.

BRASIL. Lei 10.639, de 09 de janeiro de 2003. D. O. U. de 10/01/2003. Disponível em < http://www.planalto.gov.br/ccivil 03/leis/2003/110.639.htm>. Acesso em 28 de fevereiro de 2014.

BRASIL. Lei 9.394, de 20 de dezembro de 1996. Lei de Diretrizes e Bases da Educação Nacional. Disponível em: < http://portal.mec.gov.br/arquivos/pdf/ldb.pdf $>$. Acesso em 12 de setembro de 2014.

BRASIL. MINISTÉRIO DA EDUCAÇÃO. Diretrizes Curriculares Nacionais para a Educação das Relações Étnico-Raciais e para o Ensino de História e Cultura Afro-Brasileira e Africana. Parecer CNE/CP 1/2004. Seção 1. p.11. D.O.U. de 22 de junho de 2004.

BRASIL. MINISTÉRIO DA EDUCAÇÃO / Secretaria da Educação Continuada, Alfabetização e Diversidade. Orientações e Ações para a Educação das Relações Étnico-Raciais. Brasília: SECAD, 2006.

BRASIL. Plano Nacional de Educaşão - PNE. Disponível em: http://portal.mec.gov.br/index.php?option=com_content\&id=16478\&Itemid=1107. Acesso em 02 de junho de 2015.

BRASIL. Parecer CNE / CP 003/2004. Institui as Diretrizes Curriculares Nacionais para a Educação das Relações Étnico-Raciais e para o Ensino de História e Cultura Afro-Brasileira e Africana. Disponível em: http://portal.mec.gov.br/cne/arquivos/pdf/003.pdf. Acesso em 02 de junho de 2015.

BRASIL. Constituição da República Federativa do Brasil. Disponível em http://www.planalto.gov.br/ccivil_03/constituicao/constituicaocompilado.htm. Acesso em 28 de fevereiro de 2014.

BRASIL. Lei 8.069, de 17 de janeiro de 1990. Estatuto da Criança e do Adolescente. D. O. U. 16/07/1990. 
BRASIL. Resolução n ${ }^{\circ}$ 05, de 17 de dezembro de 2009. Fixa as Diretrizes Curriculares Nacionais para a Educação Infantil. Brasília - DF.

BRASIL. Ministério da Educação e do Desporto. Secretaria de Educação Fundamental. Referencial Curricular Nacional para a Educação Infantil. Brasília: MEC/SEF, 1998. V. 1

CAVALLEIRO, Eliane. Valores civilizatórios: dimensões históricas para uma educação antirracista. In: Ministério da Educação / Secretaria da Educação Continuada, Alfabetização e Diversidade. Orientações e Ações para Educação das Relações Étnico-Raciais. Brasília: SECAD, 2006.

DIAS, Lucimar Rosa. No fio do horiz̧onte: educadora de primeira infância e o combate ao racismo. 2007. (Tese de Doutorado). Universidade de São Paulo. Faculdade de Educação, São Paulo, 2007.

FREIRE, Paulo. Pedagogia da autonomia. Saberes necessários à prática educativa. São Paulo: Paz e Terra, 1996.

GATTI, Bernadete Angelina. A construção da pesquisa em educaşão no Brasil. Brasília: Plano, 2002. (Pesquisa em Educação, v. 1).

GIROUX, Henry A. Os professores como intelectuais: rumo a uma pedagogia crítica da aprendizagem. Porto Alegre: Artmed, 1997.

LOPES, Denise Maria de Carvalho. A formação de professores para a educação infantil: evolução histórica e proporções atuais. In: Anais do X Seminário de Pesquisa do CCSA, 9, 2006, CCSA/UFRN, Natal.

MARTINS, Edna; LOURENÇO, Erica A. Garrutti. Relações étnico-raciais e a questão da deficiência na literatura infantil brasileira: uma experiência em formação de professores. Educação: Santa Maria, v. 38, n. 1, p. 205-218, jan/abr. 2013.

MELLO. Guiomar Namo de. Formação inicial de professores para a Educação Básica: uma (re) visão radical. São Paulo, outubro/novembro de 1999. Disponível em: 
http://portal.mec.gov.br/setec/arquivos/pdf/documentob\%C2\%A0sico2.pdf. Acesso em 20 de maio de 2015.

OLIVEIRA, Fabiana de. Um estudo sobre a creche: o que as práticas educativas produzem e revelam sobre a questão racial? São Carlos: UFSCar, 2004.

SILVA, Aracy Lopes; MACEDO, Ana Vera Lopes da Silva; NUNES, Angela (Orgs.). Crianças indígenas: ensaios antropológicos. São Paulo: Global, FAPESP, 2002.

SILVA, Ainda Maria Monteiro. Direitos Humanos na Educação Básica: qual o significado? In: SILVA, Ainda Maria Monteiro; TAVARES, Celma (Orgs.). Politicas e fundamentos em direitos humanos. São Paulo: Cortez, 2010, p. 41-63.

STEARNS. Peter N. A infância. Trad. Mirna Pink. São Paulo: Contexto, 2006.

Recebido em: 03 set. 2018 / Aprovado em: 15 mar. 2019

\section{Para referenciar este texto:}

CASTRO, Moacir Silva de. Relações étnico-raciais e formação docente na educação infantil. Cadernos de Pós-graduacão, São Paulo, v. 18, n. 2, p. 94-107, jul./dez. 2019. Disponível em: https://doi.org/10.5585/cpg.v18n2.10448. 